\title{
Renal Micropuncture Study of the Development of Anuria in the Rat with Mercury-induced Acute Renal Failure*
}

\author{
William J. Flanigan $\dagger$ and Donald E. Oken $\ddagger$ \\ (From the Departments of Medicine, Peter Bent Brigham Hospital and Harvard Medical \\ School, Boston, Mass.)
}

Acute renal failure in man may result from such factors as trauma, transfusion accidents, sepsis, burns, and acute poisoning with carbon tetrachloride, ethylene glycol, or mercury. Regardless of the etiology and despite marked variability in the histologic appearance of the kidneys of individual cases, most patients with acute renal failure develop oliguria or anuria together with evidence of impaired tubular function. The cause of this decrease in urine volume, however, has not been well defined. Some theories commonly conjured to explain the oliguria of acute renal insufficiency stem largely from pathological findings rather than from functional studies in vivo. Of these findings, three have been stressed as possibly being responsible for oliguria: tubular obstruction by cellular debris (1-3), tubular compression by interstitial edema (4-7), and "passive backflow" of glomerular filtrate through holes in the wall of the tubule $(6,8,9)$. We have attempted to determine the possible role of these factors in mercury-induced acute renal failure in the rat.

\section{Methods}

Sprague-Dawley rats weighing 190 to $250 \mathrm{~g}$ were placed in metabolic cages 12 to 16 hours before ex-

* Submitted for publication September 28, 1964; accepted November 27, 1964.

This work was supported by research grant AM 05505 from the National Institutes of Health, U. S. Public Health Service.

Presented in part at the meetings of the American Society for Clinical Investigation, Atlantic City, N. J., 1963.

$\dagger$ This work was performed during an Advanced Fellowship of the American Heart Association. Present address : Department of Medicine, University of Arkansas Medical School, Little Rock, Ark.

$\ddagger$ Address requests for reprints to: Dr. Donald E. Oken, Peter Bent Brigham Hospital, 721 Huntington Avenue, Boston, Mass. 02115. perimentation. Their food and fluid intake and urine volume were measured; animals whose water intake was less than $10 \mathrm{ml}$ during this period received supplementary fluids intraperitoneally in the form of $75 \mathrm{mM}$ saline. Mercuric chloride, $12 \mathrm{mg}$ per $\mathrm{ml} 140 \mathrm{mM} \mathrm{NaCl}$, was injected intramuscularly at a dose of $12 \mathrm{mg}$ per $\mathrm{kg}$, control animals receiving a comparable volume of saline alone. Micropuncture experiments were performed at times ranging from 2 to 27 hours after mercury injection, and the fluid intake and output in the intervening period were recorded. Urine osmolalities, measured cryoscopically with a Fiske osmometer, were obtained routinely in early experiments to rule out hypovolemia due to a redistribution of body water and a resultant ADH effect as the sole cause of oliguria. Since urine osmolalities in mercury-treated animals were consistently less than $610 \mathrm{mOsm}$ per $\mathrm{kg}$, these measurements later were discontinued.

Animals were anesthetized with sodium pentobarbital, $35 \mathrm{mg}$ per $\mathrm{kg}$ body weight, supplementary pentobarbital being added as necessary. They were placed supine and warmed from above with an infrared lamp to maintain body temperature at $40^{\circ} \mathrm{C}$. The left kidney was exposed through an abdominal-flank incision and gently dissected from the perirenal fat. The renal capsule was left intact, but in dissecting the kidney from its bed collateral circulation through capsular vessels was virtually abolished. The kidney was placed in a Lucite holder as gently as possible, care being taken to avoid distortion of the renal vessels and ureter. The surface of the kidney was illuminated with a 25-w zirconium arc lamp and covered with warm mineral oil to prevent surface evaporation and facilitate visualization of the renal architecture. The blood pressure of each animal was monitored with either a tail microphone apparatus or direct aortic manometry. When the tail microphone was used, a $1-\mathrm{cm}$ occluding cuff was placed at the base of the tail and the pickup positioned $1 \mathrm{~cm}$ distal to the cuff. The output of the carbon microphone was recorded on a Techtronix oscilloscope, model 502 , at a sensitivity of $200 \mu \mathrm{v}$ per $\mathrm{cm}$. Mean arterial blood pressure in anesthetized control animals varied between 80 and 105 $\mathrm{mm} \mathrm{Hg}$. To be sure that any abnormalities of renal function noted in mercury-treated animals were not related to hypotension, however, animals whose mean arterial pressure was less than $85 \mathrm{~mm} \mathrm{Hg}$ were excluded from this study. In many experiments, electrocardio- 
grams were obtained to rule out obvious mercurial myocardiopathy. The output of subcutaneous leads in the fore and rear legs was recorded on the second channel of the oscilloscope. There was no detectable difference in heart rate or QRS complex between control animals and those that had received mercury up to 12 hours earlier.

Tubular pressures were measured by manometry in a manner similar to that described by Wirz (10). Micropipettes with a tip diameter of 10 to $15 \mu$ were filled with a $10 \%$ solution of indigo carmine. A water, rather than mercury, manometer was used in these experiments to obtain maximal definition. The manometer was adjusted at zero pressure before each pressure measurement by immersing the pipette tip into a water well placed at the same height as the surface of the kidney. Proximal tubular puncture was performed in the usual fashion. The pressure at which indigo carmine did not leave and tubular content did not enter the pipette was considered the static intratubular pressure.

Glomerular filtration rate, proximal tubular water absorption, and tubular flow rate were determined at least 1 hour after the iv injection of $40 \mu \mathrm{c}$ of $\mathrm{C}^{14}$-labeled inulin. Immediately after this injection, $140 \mathrm{mM}$ saline containing $75 \mu \mathrm{c}$ of $\mathrm{C}^{14}$-inulin per $\mathrm{ml}$ was infused into the femoral vein at a rate of $0.45 \mathrm{ml}$ per hour with a Braun microperfusion pump and siliconized, precisionground syringes. Only proximal convoluted tubules were punctured in these experiments, collections being made with pipettes whose tip diameter averaged some $8 \mu$ so as to minimize the risk of leakage of tubular contents around the pipette. A drop of mineral oil stained with Sudan black was injected through the collection pipette just before the collection of the sample to prevent retrograde aspiration of tubular contents. Fluid was withdrawn from the tubule at a rate closely approximating spontaneous tubular flow by allowing the injected oil droplet to move neither towards the pipette nor distally down the tubule. Samples varied in size from 0.01 to $0.06 \mu 1$, volumes being measured in a precalibrated $0.2 \mathrm{~mm}$ i.d. constant-bore capillary tube. Meniscus error was minimized and evaporation of the samples prevented by filling the tip of the capillary with a $7: 3$ mixture of chloroform and liquid silicone. The site of each collection was assessed by the intratubular injection of latex and subsequent microdissection of the nephron in the manner described by Bott (11). Onetenth-ml blood samples were taken from the tail immediately before and after each collection period for inulin assay. Inulin- $\mathrm{C}^{14}$ activities of tubular fluid and plasma samples were measured in a Nuclear Chicago liquid counter at an efficiency of $62 \%$. The glomerular filtration rate of individual nephrons was calculated from the plasma $\mathrm{C}^{14}$-inulin concentration and the excretion rate of $\mathrm{C}^{14}$-inulin by each nephron. Water absorption was calculated from the $\mathrm{C}^{14}$ concentration ratio in tubular fluid and blood. The rate of flow of fluid in individual tubules was derived from the measured rate of collection. When greatly reduced glomerular filtration developed, volumes adequate for accurate measurement could not be obtained; flow rates were then assessed grossly by injecting a drop of stained mineral oil and observing its rate of passage down the tubules. For comparative purposes, qualitative estimates of flow rates were made in this way at time periods when flow was not yet expected to be greatly reduced. Each kidney studied was excised for histologic examination before sacrificing the animal to ensure the presence of mercurial nephropathy in treated animals subjected to micropuncture.

\section{Results}

The average urine volume of rats in the control period was $14.6 \pm 1.4 \mathrm{ml}(\mathrm{SD})$. After an initial output of up to $2 \mathrm{ml}$ within the first 4 hours, $94 \%$ of mercury-treated animals that were allowed to survive a further 24 hours excreted less than $3 \mathrm{ml}$ of urine, $33 \%$ of them being totally anuric. Most rats that did not develop oliguria (defined as less than $3 \mathrm{ml}$ per 24 hours) had, however, a reasonably normal urine volume. The mean urine output of the entire group was $1.4 \pm 3.3 \mathrm{ml}(\mathrm{SD})$ per 24 hours. Urine osmolality of the 24 -hour samples in the mercury-treated group was less than $610 \mathrm{mOsm}$ per $\mathrm{kg}$ in all but two of these animals, both of which had normal urine volumes and were, therefore, excluded from micropuncture study. Urine osmolality in the control period always exceeded $1,300 \mathrm{mOsm}$ per $\mathrm{kg}$ and averaged $1,840 \pm 280$ (SD) mOsm per $\mathrm{kg}$. It was apparent from the low osmolalities that the oliguria of mercury-treated rats was not due solely to undetected dehydration. Isosthenuria characteristic of acute renal failure in man was not observed; however, urine osmolality when measured averaged $180 \pm 30 \mathrm{mOsm}$ per $\mathrm{kg}$ more than that in plasma.

Appearance of the kidney by inspection in vivo. The kidneys appeared perfectly normal in most animals for the first 6 hours after mercury was injected. As seen under the dissecting microscope at $160 \times$ magnification, they were a normal pink color, their tubular lumina were normal in size, and tubular walls were sharply defined and clear. Capillary circulation appeared grossly normal. Thereafter, changes in appearance developed with increasing frequency and severity. By 8 to 9 hours after mercury, scattered tubules showed significant change. These tubules were pale, with granularity of the tubular cells beginning to develop. Their lumina were narrower 
than normal, and tubular flow rates typically were reduced. With the passage of time, more and more tubules showed these changes, although moderate variation in the time of development and severity of change was apparent in different animals. By 16 hours, however, kidneys of oliguric animals had a "nutmeg" appearance due to the presence of tubular segments with mild to moderate change scattered in a sea of grossly abnormal tubules. The latter were pale and coarsely granular in appearance, had extremely narrow or seemingly absent lumina, and had very poor or absent flow. They typified virtually all tubules seen at 24 to 48 hours. Debris, pale granular material resembling the tubular cell cytoplasm, was seen to pass along the nephron. With moderately brisk flow, this material sped down the tubule with no apparent tendency toward aggregation. As flow progressively decreased, however, aggregation of the detritus was seen to occur until, when tubules were virtually without flow, the material coalesced with resultant occlusion of the lumen. It seemed, therefore, that obstruction was the result of cessation of tubular flow rather than the cause of it.

The peritubular blood flow typically was not judged to be markedly reduced at any time in the first 24 hours after mercury was administered, although moderate reduction was observed in kidneys examined after 12 to 16 hours. There was no noticeable intermittency of capillary flow, nor were segmental differences in circulation noted anywhere on the kidney surface.

Proximal tubular hydrostatic pressure. Proximal tubular pressures measured in 59 experiments on 23 control animals averaged $15.6 \pm 0.3 \mathrm{~cm}$ $\mathrm{H}_{2} \mathrm{O}$ (SE), a value in good agreement with those previously reported by Wirz (10) and Gottschalk and Mylle (12). Triplicate determinations of the pressure in eight tubules showed a maximal range of $4.8 \%$ in any tubule. As shown in Figure 1, no significant change in proximal tubular pressure was detected for the first 8 hours after mercury was injected, the mean pressure being $16.2 \pm 0.6 \mathrm{~cm} \mathrm{H}_{2} \mathrm{O}$. Greater variation between animals was seen, however, as manifest in the larger standard error of the mean in this series. Eight to 13 hours after the administration of mercury, mean proximal tubular pressure in 79 experiments in 14 animals was reduced

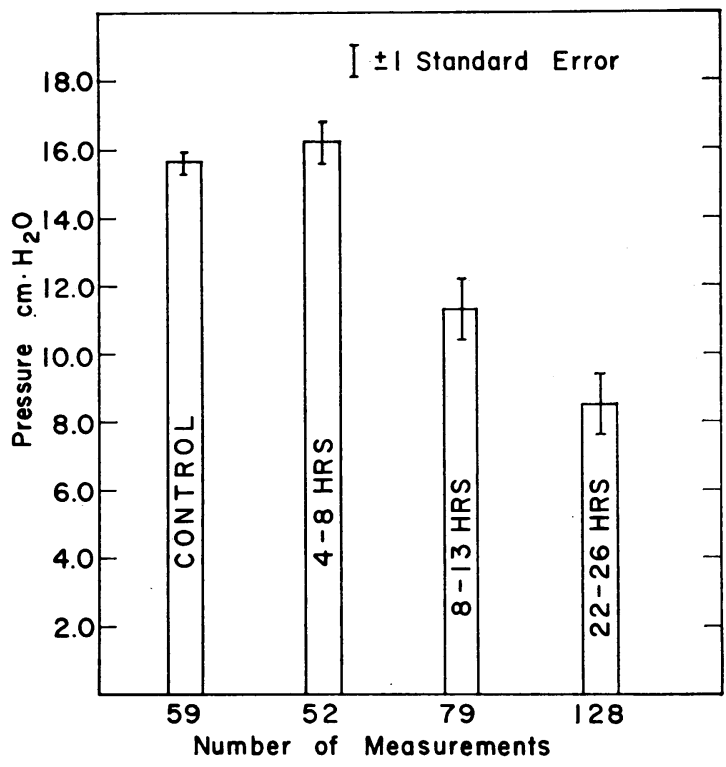

[i. ig. 1. Proximal tubular intraluminal hydroSTATIC PRESSURE IN CONTROL ANIMALS AND AT INCREASING INTERVALS AFTER MERCURY ADMINISTRATION. The number of measurements in each group is shown at the base of each column.

to $11.3 \pm 0.9 \mathrm{~cm} \mathrm{H}_{2} \mathrm{O}(\mathrm{p}<0.001)$. There was a distinct correlation between the appearance of nephrons and their intratubular pressure. Tubules that appeared normal or near normal were found to average $5.4 \mathrm{~cm} \mathrm{H}_{2} \mathrm{O}$ higher pressure than those that were pale and had diminished flow.

Pressure was further reduced to $8.5 \pm 0.5 \mathrm{~cm}$ $\mathrm{H}_{2} \mathrm{O}$ in 128 measurements on 24 animals 22 to 26 hours after mercuric chloride $(p<0.001)$. This value was derived only from those tubules that still had a discernible lumen and were not obstructed. Although accurate assessment of pressure in frankly obstructed tubules is not possible, pressures generally appeared greatly lower in frankly obstructed tubules. The kidneys of these animals showed pallor and frank desquamation of cells into the lumen; tubular flow was totally lacking in most nephrons. There was no correlation between tubular hydrostatic pressure and systemic blood pressure.

$G F R$, flow rate, and water absorption. Glomerular filtration rates (GFR) were measured in 34 tubules of 14 control animals. The GFR of this group was $42 \pm 3 \mathrm{~m} \mu \mathrm{l}$ per tubule $\cdot$ minute (SE) (Table I). GFR was measured from 5.7 
TABLE 1

Glomerular filtration rate (GFR), absolute water absorption, and flow rate measured in individual nephrons of control animals and those that had received mercury approximately 6 hours earlier

\begin{tabular}{|c|c|c|c|}
\hline & GFR & Absolute water absorption & Tubular flow rate \\
\hline & $m \mu l / t u b u l e \cdot \min$ & $m \mu l \%$ tubule length & $m \mu l / t u b u l e \cdot m i n$ \\
\hline Control & $42 \pm 3(\mathrm{SE})$ & $0.37 \pm 0.02(\mathrm{SE})$ & $20.7 \pm 4.0(\mathrm{SE})$ \\
\hline \multirow[t]{2}{*}{ Mercury } & $19 \pm 5$ & $0.17 \pm 0.03$ & $12.9 \pm 1.3$ \\
\hline & I)ifference $\mathrm{p}<0.001$ & $\mathrm{p}<0.001$ & $\mathrm{p}<0.001$ \\
\hline
\end{tabular}

hours to 8.3 hours (mean 6.1 hours) after mercury was administered to ten rats. The mean filtration rate in 23 tubules was $19 \pm 5 \mathrm{~m} \mu \mathrm{l}$ per tubule minute, a value significantly lower than that of controls $(p<0.001)$.

As shown in Table I, a significant decrease in flow rate was detectable in these tubules $(p<$ $0.001)$. Nean flow rate in 40 tulunles of 17 control animals was $20.7 \pm 4.0 \mathrm{~m} \mu \mathrm{l}$ per minute (SE), whereas that measured 6 hours after mercury in 2.3 tubules of ten rats was $12.9 \pm 1.3 \mathrm{~m} \mu \mathrm{l}$ per minute. The qualitative estimation of tubular flows determined by eye is shown in Figure 2 . Flow was graded as $0,1,2$, or $3+, 3+$ being normal flow and 0 being absence of flow. Flow was markedly diminished or absent in $16 \%$ of 52 tubules examined + to 8 hours after mercury was injected and was diminished in an additional $64 \%$. Between $\&$ and 13 hours after mercury, however, $50 \%$ of nephrons showed decreased flow, $29 \%$ having virtually no flow. At 24 hours, $85 \%$ of 128 nephrons in 23 animals had no detectable flow, the remaining $15 \%$ having diminished flow. In a few instances where flow was judged to be near normal, the kidney did not have the typical appearance of mercury nephropathy, and tubular pressures were not grossly reduced. These values. therefore, were excluded from the series. Such kidneys, found in four oliguric animals, had the appearance of animals studied 6 to $\&$ hours after mercury. The explanation for their appearance is unknown. It is possibly due to leakage of mercury from the injection site, since the rate of progression of changes in the kidney has been shown to be a function of mercury dosage (13).

Water absorption was determined from the inulin tubular fluid/plasma $(\mathrm{TF} / \mathrm{P})$ ratio in 16 proximal tubules of seven control animals and in 15 tubules of ten animals 6 hours after mercury injection. As may be seen from figure 3, there

INTRATUBULAR FLOW RATES

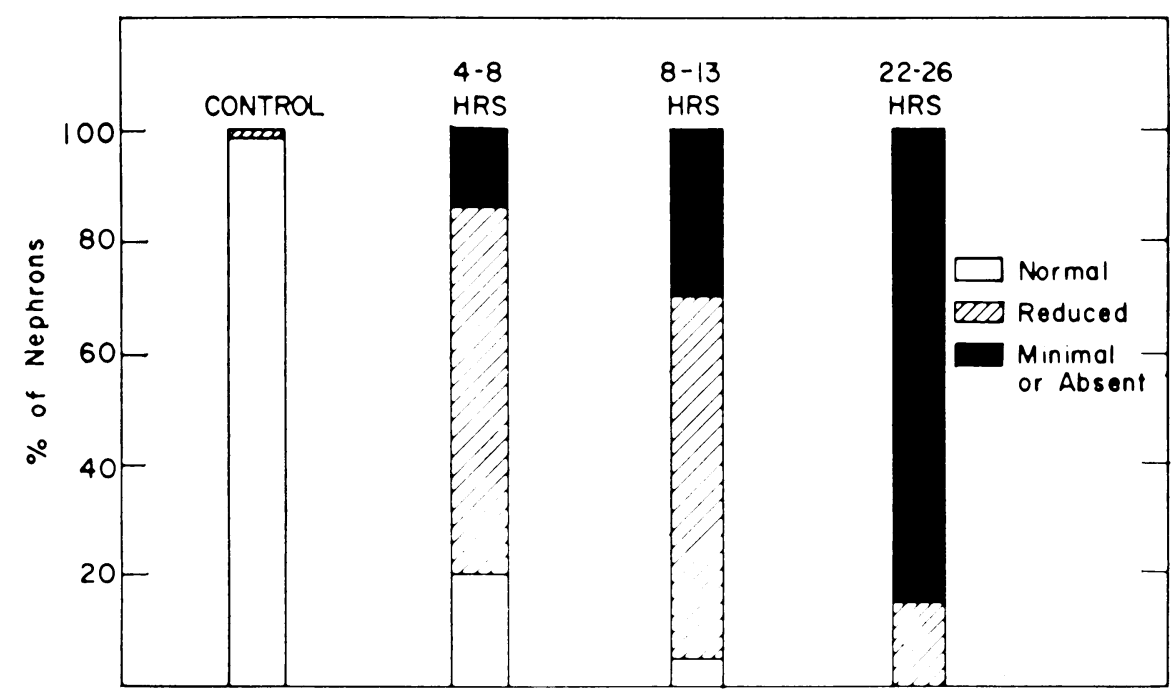

Fig. 2. Qualitative estimate of proximal, tubular fiow kate iN control and MERCURY-TREATED ANIMALS. The number of observations in each group is the same as in Figure 1. 
was no apparent difference in fractional water absorption per unit tubular length. The spread of data in both groups was quite wide. Absolute values for water absorption (fractional water $a b-$ sorption $\times$ GFR) at various sites of the proximal tubule were, however, statistically different $(\mathrm{p}<$ 0.001 ), being $0.37 \pm 0.02 \mathrm{~m} \mu \mathrm{l}(\mathrm{SE})$ and $0.17 \pm$ $0.03 \mathrm{~m} \mu \mathrm{l}$ per cent of tubular length in control and mercury-treated animals respectively.

It was not possible to obtain quantitative estimates of water absorption when oliguria was well established, since volumes adequate for inulin assay could not be obtained. In a number of cases, however, a segment of $140 \mathrm{mM}$ saline was injected into a tubule between oil droplets and the rate of absorption observed. Absorption was seen to decrease progressively with time, being almost nonexistent 24 hours after mercury injection.

\section{Discussion}

Regardless of its cause, acute renal failure in man is characterized by impaired tubular function and severe oliguria. Although comparable abnormalities of the renal parenchyma may be produced in many ways in the laboratory, most experimental models are characterized by polyuria rather than oliguria. Mercury poisoning, however, predictably produces oliguria, $94 \%$ of wellhydrated animals in this study developing severe oliguria or total anuria within 24 hours after mercury was given. A similar proportion of rats was reported by Sims, Goldberg, Kelly, and Sisco to develop oliguria after this dose of mercury (14). In attempting to discover the factors that contribute to the development of oliguria in experimental acute renal failure, it is essential that a model be used in which both the anatomic and the functional changes are consistent in their time of onset and rate of progression. Mercury poisoning was chosen for these experiments because it fulfills these criteria. Furthermore, present concepts of the pathophysiology of anuria have been influenced considerably by other studies utilizing this means of producing acute renal failure. We felt, therefore, that conclusions so derived warrant direct examination. It should be stressed at the onset, however, that the events which occur in $\mathrm{HgCl}_{2}$-induced nephropathy hold no necessary correlation with those occurring in

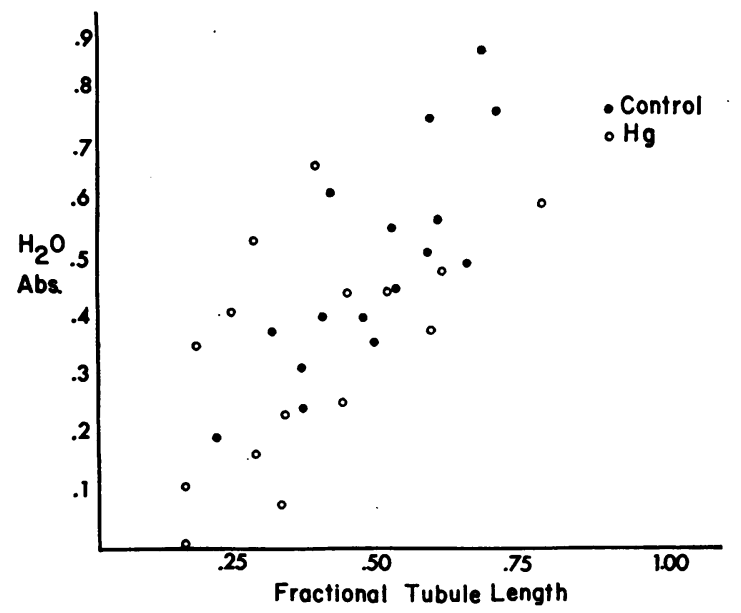

Fig. 3. Fraction OF FILTERED VOLUME ABSORBED IN INDIVIDUAL PROXIMAL TUBULES RELATED TO SITE OF SAMPLE COLLECTION. There is no statistical difference between control values and those obtained 5.7 to 8.3 hours after mercury had been injected.

man as a result of transfusion reactions, septic abortion, crush injuries, burns, or the myriad other causes of acute renal failure.

Histologic examination of the kidney in acute renal failure usually discloses lesions that may account for the observed impairment of tubular function. No consistent alteration of the glomeruli that might explain the decreased urine volume has been described, however, in either light or electron microscopy studies (15). It is not surprising, therefore, that the oliguria of acute renal failure also has been attributed to tubular lesions $(1-3,6,8,9)$. These lesions, which may be seen in acute renal failure of both man and experimental animals, include disruption of tubular cells, interstitial edema, and the presence of intraluminal casts. Each has been incriminated as a possible cause of oliguria. There is not a close correlation, however, between histologic findings and the development of oliguric renal failure (6, 16-18). In a controlled autopsy study, Finckh, Jeremey, and Whyte found instances of acute renal failure associated with minimal abnormalities of the tubules, although kidneys of some patients who did not have renal failure had relatively severe tubular lesions. Nor is there any necessary correlation between the degree of functional impairment and the histologic appearance of the kidney in renal biopsy specimens taken 2 to 66 days after the onset of anuria (19). 
The concept of a tubular basis for oliguria receives support from a widely quoted micropuncture study of Richards (20). This brief report published in 1929 states that frogs injected with mercury developed anuria at a time when their GFR was normal or increased. Unfortunately, the means by which the rate of formation of both glomerular filtrate and urine was assessed in this study was not stated. Information on the dose and route of administration of mercury was not given, nor was there any mention of the time interval between mercury injection and the onset of anuria. Oliver also has studied urine formation in frogs poisoned with mercuric chloride that was perfused through their separate glomerular and tubular circulations (21). When $10 \mathrm{ml}$ of $1: 10,000$ corrosive sublimate in Locke's solution was perfused through the renal arteries to the glomeruli, a prompt decrease in the urine volume to approximately one-third of control values was observed. When, however, the peritubular circulation was perfused with mercury by way of the renal portal vein, urine volume increased almost fourfold. These results are diametrically opposed to those reported by Richards.

If anuria were the result of complete absorption of glomerular filtrate formed at a normal or near normal rate, how might this occur? Water absorption by the proximal tubule has been shown to be a totally passive process secondary to the active transport of sodium (20-24). An increase in active sodium transport due to mercury poisoning is highly unlikely, mercury having been shown to inhibit active transport processes rather than enhance them (25-27). A means of promoting passive transport must, therefore, be considered. Significant absorption of proximal tubular content cannot occur by diffusion, since there is no real concentration difference between most of the contents of plasma and the glomerular filtrate. If tubules whose sodium transport capabilities were lost retained their normal capacity to absorb glucose, only a little more than $0.5 \%$ of the total volume of filtrate would diffuse from the tubule in response to the minimal resultant change in tubular fluid osmolality. Such forces as electroosmosis and thermal gradients have not been shown to be important in biological systems and may be excluded from our consideration. Transtubular hydrostatic pressure gradients and the possible effect of the oncotic pressure of plasma in peritubular capillaries remain to be considered. According to one theory, tubular contents normally are absorbed passively as a result of the colloid oncotic pressure of peritubular capillary blood in a manner analogous to the return of interstitial fluid into the muscle capillary $(28,29)$. In normal Necturus, such a phenomenon has been effectively disproved, absorption of tubular contents continuing despite the introduction into the proximal tubule of fluid with a protein concentration $50 \%$ greater than that of plasma (24). Similar results have been obtained in normal rat proximal tubules (30). Colloid oncotic pressure, some $35 \mathrm{~cm}$ of water, is a not inconsiderable force for water absorption across such highly waterpermeable structures as capillaries. The water permeability of normal proximal tubules, however, may be calculated to be orders of magnitude less than that of a capillary. Furthermore, the gradient for fluid absorption into capillaries is great, only the thickness of the capillary wall being interposed between the plasma and the fluid to be resorbed. In the case of the nephron, on the other hand, the gradient is relatively small, the tubular cell and renal interstitium also being interposed between the lumen content and the peritubular blood. An increased permeability of the tubule has been postulated to occur in acute renal failure, however, which might facilitate the absorption of lumen contents either by this mechanism $(6,8,9)$ or as the result of a transtubular hydrostatic pressure difference.

No difference between the hydrostatic pressure of the tubule and the peritubular capillaries has been found in normal rat kidneys, suggesting that there is no significant hydrostatic pressure gradient between tubules and interstitium $(10,12)$. This is to be expected. The tubules being both collapsible and distensible and the interstitial fluid having a ready source of egress through the renal lymphatics and veins, equilibration of pressure differences between tubules and interstitium should occur promptly. Regardless of theoretic considerations, increased proximal tubular absorption of water was not seen at any phase of this study of mercury-induced oliguria. Fractional net water absorption in the first 6 to 8 hours after mercury was not statistically different from that of controls. Although mean water ab- 
sorption averaged some $25 \%$ less than control values, the wide spread of the data obviated any statistical significance that otherwise might have obtained. Nonetheless, with glomerular filtration in mercury-treated animals reduced by one-third, values for absolute water absorption in these animals were significantly lower than those of controls. Later, when oliguria was well established, fluid absorption from the proximal tubules, determined directly from the rate of absorption of an injected drop of $140 \mathrm{mM}$ saline, was virtually absent. It is apparent, therefore, that tubular "backflow" cannot play a significant role in the oliguria of mercury-induced acute renal failure in the rat.

Tubular obstruction with casts or cell debris also has been claimed to contribute to oliguria in acute renal failure by increasing intratubular pressure. The significance of casts in the genesis of oliguria in man has been questioned, however, on the grounds of their relative infrequency in histologic sections $(6,18)$. In the present experiments, glomerular filtration rate was shown to fall without any demonstrable increase in intratubular pressure. To the contrary, intratubular pressure decreased steadily until, 24 hours after the administration of mercury, it averaged only $54 \%$ of control values. Thus obstruction per se cannot account for the observed decrease in GFR; rather, with the passage of time detritus was seen to appear in the tubular lumina. At first when flow was not markedly altered, the particulate matter was swept rapidly through the tubule without apparent aggregation. As flow through the tubules progressively decreased, debris tended to aggregate more and more. Between 16 and 24 hours after mercury, when flow was almost completely absent, the tubular lumen tended to become totally occluded. It appears, therefore, that tubular obstruction is the result, rather than the cause, of diminished flow.

In evaluating the significance of a decreased intratubular hydrostatic pressure in these experiments, the possibility of obstruction proximal to the site of pressure measurement must be considered. Micropuncture studies were performed at sites varying from $16 \%$ to $77 \%$ of total proximal tubular length. If undetected partial obstruction occurred in the inaccessible first $20 \%$ of the tubule, the intracapsular pressure of the glomerulus might be high while a low pressure is measured distal to the obstruction. However, histologic examination of kidneys obtained 8 to 16 hours after mercury, a time when proximal tubular pressure was already reduced, generally did not show occlusion of tubules, nor was obvious cast material found in proximal segments at the time of microdissection. The assumption that pressures measured in these experiments are not factitiously low and mirror capsular pressures, therefore, seems valid.

Glomerular filtration was observed to be impaired within 6 hours after mercury administration. The validity of measurements of GFR in individual nephrons utilizing inulin clearance may be challenged, however, because of the possibility of inulin loss across damaged tubular walls. The reduction in GFR in these experiments began long before gross disruption of the tubular epithelium had occurred. Furthermore, since flow rates determined at a time when GFR was already grossly reduced still averaged $62 \%$ of control values, transit time from glomerulus to collection site was only a matter of seconds. The mean inulin $\mathrm{TF} / \mathrm{P}$ of mercury-treated animals at this time was 1.6. In view of this low transtubular inulin concentration difference, as well as the small inulin-free diffusion coefficient $\left(0.3 \times 10^{-5}\right.$ $\mathrm{cm}^{2} \mathrm{sec}^{-1}$ ) and the short time of exposure of filtrate to the tubular wall, net diffusion of a large amount of inulin across the tubule would seem rather unlikely even if tubular integrity were significantly impaired. Within 24 hours after mercury administration, moreover, proximal tubular fluid flow rates were insignificantly small. Since absorption of isosmolar fluid injected into the tubule was seen to be grossly diminished (rather than augmented) at this time, it must be inferred that the GFR also was extremely small and that the decrease and ultimate cessation of GFR were the primary causes of oliguria in these experiments.

No abnormality in glomerular anatomy has been demonstrated in acute renal failure (15). Although decreased glomerular permeability is not ruled out by this fact, it is unlikely that glomerular filtration would virtually cease on this basis without some abnormality of glomerular structure being demonstrated on electron microscopy. One must postulate, therefore, a vascular 
basis for the cessation of glomerular filtration. Hypotension is ruled out as a cause of the decreased GFR in these experiments, since micropuncture was not performed on animals with a mean arterial blood pressure lower than $85 \mathrm{~mm}$ Hg. Preglomerular vascular constriction, postglomerular dilitation, preglomerular shunting, or a combination of these factors remains as a possible cause of the observed decrease. There are no data to be derived from this study that might differentiate among these possibilities. In the present experiments, the peritubular circulation was judged visually to be not greatly diminished in most animals 12 to 24 hours after mercury, nor was circulatory intermittency observed. Furthermore, the function of several tubules, often at widely scattered points of the kidney surface, was studied in each rat. Although there was variation in the function of nephrons in the same kidney, marked functional disparity between nephrons as suggested by the intact nephron hypothesis or intra-renal shunting was not observed. It would appear that the capillary circulation of the surface nephrons, at least, was relatively homogeneous.

\section{Summary}

The physiologic events leading to the development of anuria in $\mathrm{HgCl}_{2}$-induced acute renal failure have been studied in the rat. Glomerular filtration becomes progressively decreased as oliguria develops. Absorption of proximal tubular fluid and intratubular pressure also decrease progressively. Tubular obstruction due to cast formation or interstitial edema and passive backflow of the filtrate were shown to play no significant role in the development of anuria. Rather, tubular obstruction with detritus appears to be the result of the decreased glomerular filtration rate (GFR) and diminished tubular flow. A primary decrease in GFR is thus suggested as the initial cause of anuria in $\mathrm{HgCl}_{2}$-poisoned rats.

\section{References}

1. Baker, S. L., and E. C. Dodds. Obstruction of the renal tubules during the excretion of hæmoglobin. Brit. J. exp. Path. 1925, 6, 247.

2. Bywaters, E. G. L., and D. Beall. Crush injuries with impairment of renal function. Brit. Med. J. 1941, 1, 427.
3. Meroney, W. H., and M. E. Rubini. Kidney function during acute tubular necrosis: clinical studies and a theory. Metabolism 1959, 8, 1.

4. Abeshouse, B. S. Renal decapsulation. A review of the literature and a report of ten cases. J. Urol. (Baltimore) 1945, 53, 27.

5. Peters, J. T. Oliguria and anuria due to increased intrarenal pressure. Ann. intern. Med. 1945, 23, 221.

6. Oliver, J., M. MacDowell, and A. Tracy. The pathogenesis of acute renal failure associated with traumatic and toxic injury. Renal ischemia, nephrotoxic damage and the ischemuric episode. J. clin. Invest. 1951, 30, 1307.

7. Merrill, J. P. Kidney disease: acute renal failure. Ann. Rev. Med. 1960, 11, 127.

8. Dunn, J. S., M. Gillespie, and J. S. F. Niven. Renal lesions in two cases of crush syndrome. Lancet 1941, 2, 549.

9. Govaerts, P. The ratio of creatinine clearance to urea clearance in toxic nephropathies. Stanf. med. Bull. $1948,6,71$.

10. Wirz, H. Druckmessung in Kapillaren und Tubuli der Niere durch Mikropunktion. Helv. physiol. pharmacol. Acta 1955, 13, 42.

11. Bott, P. A. Renal excretion of creatinine in Necturus. A reinvestigation by direct analysis of glomerular and tubule fluid for creatinine and inulin. Amer. J. Physiol. 1952, 168, 107.

12. Gottschalk, C. W., and M. Mylle. Micropuncture study of pressure in the proximal tubules and peritubular capillaries of rat kidney and the relationship to ureteral and renal venous pressures. Amer. J. Physiol. 1956, 183, 430.

13. Schamberg, J. F., J. A. Kolmer, and G. W. Raiziss. A study of the comparative toxicity of the various preparations of mercury. With a histological study of experimental mercurial nephritis. J. cutan. Dis. 1915, 33, 819.

14. Sims, E. A. H., H. I. Goldberg, J. R. Kelly, and B. Sisco. Glomerular perfusion during acute renal insufficiency from mercury poisoning in the rat. J. Lab. clin. Med. 1959, 54, 440.

15. Dalgaard, O. Z., and K. J. Pedersen. Renal tubular degeneration: electron microscopy in ischæmic anuria. Lancet 1959, 2, 484.

16. DeGowin, E. L., E. D. Warner, and W. L. Randall. Renal insufficiency from blood transfusion. II. Anatomic changes in man compared with those in dogs with experimental hemoglobinuria. Arch. intern. Med. 1938, 61, 609.

17. Sevitt, S. Pathogenesis of traumatic uræmia. A revised concept. Lancet 1959, 2, 135.

18. Finckh, E. S., D. Jeremy, and H. M. Whyte. Structural renal damage and its relation to clinical features in acute oliguric renal failure. Quart. J. Med. 1962, 31, 429.

19. Brun, C., and O. Munck. Lesions of the kidney in acute renal failure following shock. Lancet 1957, 1, 603. 
20. Richards, A. N. Direct observations of change in function of the renal tubule caused by certain poisons. Trans. Ass. Amer. Phycns 1929, 44, 64.

21. Oliver, J. Experimental nephritis in the frog: IV. The significance of the functional response to vascular and to parenchymal disturbances in the kidney. J. exp. Med. 1932, 55, 295.

22. Windhager, E. E., and G. Giebisch. Micropuncture study of renal tubular transfer of sodium chloride in the rat. Amer. J. Physiol. 1961, 200, 581.

23. Gottschalk, C. W., and M. Mylle. Micropuncture study of pressures in proximal and distal tubules and peritubular capillaries of the rat kidney during osmotic diuresis. Amer. J. Physiol. 1957, 189, 323.

24. Oken, D. E., G. Whittembury, E. E. Windhager, and A. K. Solomon. Single proximal tubules of $\mathrm{Nec}$ turus kidney. V: Unidirectional sodium movement. Amer. J. Physiol. 1963, 204, 372.

25. Kleinzeller, A., and J. H. Cort. The mechanism of action of mercurial preparations on transport processes and the role of thiol groups in the cell membrane of renal tubular cells. Biochem. J. 1957, 67, 15.

26. Clarkson, T. W., and A. Cross. Studies of the action of mercuric chloride on intestinal absorption. Univ. of Rochester AEC Report no. 588, 1961.

27. Linderholm, $H$. Active transport of ions through frog skin with special reference to the action of certain diuretics. A study of the relation between electrical properties, the flux of labelled ions and respiration. Acta physiol. scand. 1952, 27 (suppl. 97).

28. Vogel, G., and E. Heym. Untersuchungen zur Bedeutung kolloidosmotischer druckdifferenzen für den Mechanismus der isosmotischen Flússigkeirsresorption in der Niere. Pflúgers Arch. ges. Physiol. 1956, 262, 226.

29. Vander, A. J., R. L. Malvin, W. S. Wilde, and L. P. Sullivan. Re-examination of salt and water. retention in congestive heart failure. Significance of renal filtration fraction. Amer. J. Med. 1958, 25, 497.

30. Oken, D. E. Unpublished data. 